\title{
Thyroid Function and Volume are Associated with Anthropometric Measurements and Insulin Resistance in Egyptian Women with Polycystic Ovary Syndrome
}

Hala A Abd El-Hafez ${ }^{1 *}$, Mohamed M Elrakhawy², Sherin Abd El-Aziz ${ }^{3}$ and Mervat M El-Eshmawy ${ }^{1}$

${ }^{1}$ Internal Medicine Department, Mansoura Specialized Medical Hospital, Mansoura University, Egypt

${ }^{2}$ Radiology Department, Mansoura University Hospital, Mansoura University, Egypt

${ }^{3}$ Clinical Pathology Department, Mansoura University Hospital, Mansoura University, Egypt

\begin{abstract}
Background: Polycystic ovary syndrome (PCOS) is frequently associated with insulin resistance (IR) and obesity. On the other hand, obesity has been previously linked to endocrine disorders especially thyroid dysfunction. The purpose of this study was to assess thyroid function and volume in women with PCOS and to evaluate their relations to anthropometric measurements and IR.

Methods: The study enrolled 40 women with PCOS and 62 healthy women matched for age and body mass index (BMI). BMI, waist circumference (WC), homeostasis model assessment of Insulin resistance (HOMA-IR), lipid profile, androgens, thyroid function tests and thyroid volume were evaluated. PCOS women were divided according to HOMA-IR into 2 subgroups: non-insulin resistant and insulin resistant PCOS.

Results: Insulin resistant PCOS; but not total or non-insulin resistant PCOS; had significant increase in TSH, thyroid volume, and nodule prevalence than control women. Insulin resistant PCOS showed significant increase in BMI, WC, TSH and thyroid volume than non-insulin resistant PCOS. In PCOS women: TSH, thyroid volume and nodule prevalence were significantly and positively correlated with BMI, WC, fasting insulin and HOMA-IR. With multiple regression analysis BMI, WC, fasting insulin and HOMA-IR remained independently correlated with TSH, thyroid volume and nodule prevalence.
\end{abstract}

Conclusions: Women with PCOS had changes in thyroid function and volume which are linked to and associated with IR. Obesity may represent a link between IR and thyroid changes in these women.

Keywords: PCOS; Anthropometric measurements; IR; Thyroid function; Thyroid volume

Abbreviations: PCOS: Polycystic Ovary Syndrome; NIR-PCOS: Non Insulin Resistant PCOS; IR-PCOS: Insulin Resistant PCOS; CVD: Cardiovascular Disease; IR: Insulin Resistance; BMI: Body Mass Index; WC: Waist Circumference; SBP: Systolic Blood Pressure; DBP: Diastolic Blood Pressure; HOMA-IR: Homeostasis Model Assessment Of Insulin Resistance; HDL-C: High Density Lipoprotein Cholesterol; LDL-C: Low Density Lipoprotein Cholesterol; TT: Total Testosterone; DHEAS: Dehydroepiandrosterone Sulphate; SHBG: Sex Hormone Binding Globulin

\section{Introduction}

Polycystic ovary syndrome (PCOS) is a common endocrine and metabolic disease affecting $6-8 \%$ of reproductive age women $[1,2]$. It is characterized by hyperandrogenism, chronic anovulation and polycystic ovaries after exclusion of related disorders [3]. PCOS women frequently exhibit abdominal obesity, hyperinsulinemic insulin resistance, and other features of metabolic syndrome including dyslipidemia and hypertension, with increased risk for type 2 diabetes and cardiovascular disease (CVD) $[2,4,5]$.

Insulin resistance (IR) plays a central role in PCOS as a cause or a consequence [6]. Approximately $50-70 \%$ of PCOS women are insulin resistant [4]. Obesity is a risk factor for insulin resistance in PCOS women [7], and it has been also linked to endocrine disorders especially thyroid dysfunction [8]. On the other hand, thyroid function even within euthyroid range has been linked to insulin resistance and metabolic syndrome $[9,10]$. In addition, increased thyroid volume and nodular gland percentage was reported in euthyroid women with IR [11].

Data regarding the relation of insulin resistance with thyroid function and volume in PCOS are limited and inconsistent. Subclinical hypothyroidism was not associated with phenotype expression or insulin resistance in PCOS in one study [12]. In contrast, other data support close relation between ovary function, thyroid function, and insulin resistance [13], moreover thyroid function as reflected by TSH levels was associated with IR in PCOS women [14]; however, this was not compared with non-PCOS women.

This study was conducted to assess thyroid function and volume in women with PCOS and to evaluate their relations to anthropometric measurements and insulin resistance.

*Corresponding author: Hala A Abd El-Hafez, Internal Medicine Department Mansoura Specialized Medical Hospital, Mansoura University, Gomhoria Street Mansoura, Dakhlia B.O.Pox 35516, Egypt, E-mail: hala_ahmed204@yahoo.com

Received May 20, 2013; Accepted September 04, 2013; Published September 10,2013

Citation: El-Hafez HAA, Elrakhawy MM, El-Aziz SA, El-Eshmawy MM (2013) Thyroid Function and Volume are Associated with Anthropometric Measurements and Insulin Resistance in Egyptian Women with Polycystic Ovary Syndrome. J Diabetes Metab 4: 288. doi:10.4172/2155-6156.1000288

Copyright: (C) $2013 \mathrm{El-Hafez} \mathrm{HAA}$, et al. This is an open-access article distributed under the terms of the Creative Commons Attribution License, which permits unrestricted use, distribution, and reproduction in any medium, provided the original author and source are credited. 
Citation: El-Hafez HAA, Elrakhawy MM, El-Aziz SA, El-Eshmawy MM (2013) Thyroid Function and Volume are Associated with Anthropometric Measurements and Insulin Resistance in Egyptian Women with Polycystic Ovary Syndrome. J Diabetes Metab 4: 288. doi:10.4172/21556156.1000288

Page 2 of 5

\section{Subjects and Methods}

The study comprised 40 middle aged women with PCOS and 62 healthy women matched for age and body mass index (BMI) (Table 1). PCOS women were recruited from Endocrinology, and Obesity outpatient clinics at Mansoura Specialized Medical Hospital, Mansoura University, Egypt. All subjects signed an informed consent to be included in our study. The study was approved by the local ethical committee.

PCOS was diagnosed according to Rotterdam revised Criteria [3] after exclusion of other causes of hyperandrogenism and menstrual irregularities as well as thyroid disease: women with PCOS had amenorrhea or oligomenorrhea and/or clinical (hirsutism with Ferriman-Gallwey Score >7, acne) [15] and/or biochemical hyperandrogenism (increased circulating level of free [FT] or total testosterone [TT] or dehydroepiandrosterone sulphate [DHEAS], and polycystic ovaries on ultrasound scan (at least one ovary more than 10 $\mathrm{ml}$ and/or with at least 12 follicles of 2 to $9 \mathrm{~mm}$ in diameters).

Control Women had no menstrual irregularities, family history of PCOS or signs of hyperandrogenism. Normal ovulation was assessed by measurement of progesterone on days 22-23 of the menstrual cycle. None of the participants were diabetic, or used medications (hormonal therapy, steroids, and lipid lowering or insulin sensitizers for at least 3 months).

All participants were subjected to complete medical history including menstrual cyclicity, family history, and medications. Complete physical examination was performed with stress on signs of hyperandrogrenism and anthropometric measures including weight, height, BMI calculated as weight $/$ height $^{2}\left[\mathrm{~kg} / \mathrm{m}^{2}\right]$, and waist circumference (WC) (measured at the level of the iliac crest at the end of normal expiration).

\section{Laboratory assay}

Fasting plasma glucose was determined using Spinreact kit, (SPAIN). Quantitative determination of insulin was done by enzyme amplified sensitivity immunoassay using INS-EASIA kit (Biosource, Europe and Belgium). Homeostasis model assessment of insulin resistance (HOMA-IR) was calculated with the formula: HOMA$\mathrm{IR}=$ fasting insulin $(\mu \mathrm{U} / \mathrm{ml}) \times$ fasting glucose $(\mathrm{mmol} / \mathrm{L}) / 22.5)[16]$. To identify IR in PCOS women; HOMA values of the control group used to define upper control values using the mean +2 standard deviation as previously described $[17,18]$, accordingly normal limit for HOMA was $<2.87$. Serum total cholesterol, high density lipoprotein cholesterol (HDL-C) and triglyceride (TG) were assessed using commercially available kits supplied by human (Germany). Low density lipoprotein cholesterol (LDL-C) was calculated according to Friedewald equation [19]. The electro-chemiluminescence immunoassay (ECLIA) for the in vitro quantitative determination of $\mathrm{LH}, \mathrm{FSH}$, Total testosterone and DHEAS in human serum and plasma on the Elecsys 2010 (Germany) using Elecsys kits [20]. Direct quantitative determination of free testosterone detected with enzyme linked immunoassay (ELISA) technique using Diagnostic Biochem Canada Inc. [21]. Quantitative determination of thyroid stimulating hormone (TSH) was done by enzyme immunoassay using BioCheck, Inc Kit [22]. Quantitative measurement of non protein- bound thyroxine (Free T4) levels in serum was done by IMMULITE ${ }^{\circ}$ chemiluminescent enzyme immunoassay system [23].

Thyroid ultrasonography was performed using high frequency linear probe $5-12 \mathrm{MHz}$ of ATL HDI 500 machine, USA. Subjects examined in supine position with a small pillow placed under their shoulders especially in obese with short neck for better exposure of the thyroid gland. Scanning was done in longitudinal and transverse planes allowing measurements of length, width, and depth of each lobe as well as the isthmus separately, then volume of each one obtained either automatically or using the equation: thyroid volume $(\mathrm{ml})=$ length $(\mathrm{cm}) \times$ width $(\mathrm{cm}) \times$ depth $(\mathrm{cm}) \times 0.52$, lastly all added together to get average thyroid volume (Figure 1 ).

\section{Statistical methods}

Statistical analysis of data was done by using SPSS program. The data were expressed as mean \pm SD for continuous data, frequency and proportion for categorical data. Student's t-test was used for comparison of quantitative data of two groups. A chi-square test was used to compare categorical data. Pearson correlation coefficient was done to study relation between different items. Multiple regression analysis was also performed with TSH, thyroid volume and nodule as the dependent variables and other variables (BMI, WC, SBP, fasting insulin, HOMA-IR, triglyceride and total testosterone) as independent variables. $\mathrm{P}<0.05$ was considered as significant.

\begin{tabular}{|c|c|c|c|c|}
\hline Variables & Controls $(n=62)$ & Total PCOS $(n=40)$ & NIR-PCOS (n=22) & IR-PCOS $(n=18)$ \\
\hline Age (ys) & $26.5 \pm 6.4$ & $27.7 \pm 5.9$ & $28.6 \pm 6.9$ & $26.9 \pm 5.3$ \\
\hline BMI $\left(\mathrm{kg} / \mathrm{m}^{2}\right)$ & $27.31 \pm 5.2^{\mathrm{b}^{*}}$ & $28.8 \pm 5.52$ & $27.22 \pm 4.92^{\mathrm{b}^{*}}$ & $30.86 \pm 5.93$ \\
\hline WC $(\mathrm{cm})$ & $86.12 \pm 10.31^{a, b^{* \star}}$ & $92.28 \pm 11.9$ & $88.11 \pm 10.38^{b^{*}}$ & $96.5 \pm 13.39$ \\
\hline $\mathrm{SBP}(\mathrm{mmHg})$ & $116.2 \pm 9.4^{\mathrm{a}, \mathrm{b}^{*}}$ & $121.8 \pm 12$ & $118.9 \pm 10.2$ & $124.5 \pm 14.1$ \\
\hline $\mathrm{DBP}(\mathrm{mmHg})$ & $78.2 \pm 8.4$ & $80.5 \pm 9.1$ & $79.2 \pm 8.6$ & $82.2 \pm 9.4$ \\
\hline Fasting glucose (mg/dl) & $89.8 \pm 10.61^{\mathrm{b}^{*}}$ & $93.9 \pm 11.7$ & $92.2 \pm 10.3$ & $96.92 \pm 13.4$ \\
\hline Fasting insulin $(\mu \mathrm{U} / \mathrm{L})$ & $7.24 \pm 2.4^{\mathrm{a}, \mathrm{b} * \star}$ & $10.9 \pm 3.05$ & $7.5 \pm 2.60^{b * *}$ & $14.91 \pm 3.6$ \\
\hline HOMA-IR & $1.65 \pm 0.61^{\mathrm{a}, \mathrm{b} * *}$ & $2.61 \pm 0.86$ & $1.75 \pm 0.83^{b * *}$ & $3.75 \pm 0.81$ \\
\hline Total cholesterol (mg/dl) & $169.32 \pm 32.93$ & $180.3 \pm 37.42$ & $172.64 \pm 34.25$ & $189.12 \pm 39.56$ \\
\hline Triglycerides (mg/dl) & $112.96 \pm 29.1^{a \mathrm{~b}^{\star}}$ & $125.7 \pm 31.43$ & $114.01 \pm 31.04^{b *}$ & $135.31 \pm 32.31$ \\
\hline $\mathrm{HDL}-\mathrm{C}(\mathrm{mg} / \mathrm{dl})$ & $55.43 \pm 8.05^{\mathrm{b}^{\star}}$ & $53.31 \pm 6.15$ & $55.54 \pm 5.21^{\mathrm{b}^{*}}$ & $51.2 \pm 7.12$ \\
\hline LDL-C (mg/dl) & $94.6 \pm 28.2$ & $102.3 \pm 28.55$ & $95.4 \pm 25.3$ & $110.71 \pm 32.52$ \\
\hline Total Testosterone(nmol/L) & $1.71 \pm 0.72^{\mathrm{a}, \mathrm{b}, \mathrm{c}, \mathrm{c}^{* *}}$ & $2.45 \pm 1.1$ & $2.30 \pm 0.92$ & $2.58 \pm 1.3$ \\
\hline DHEAS $(\mu \mathrm{mol} / \mathrm{L})$ & $5.12 \pm 2.15^{\mathrm{b}^{*}}$ & $5.93 \pm 2.64$ & $5.21 \pm 2.85$ & $6.70 \pm 2.55$ \\
\hline SHBG (nmol/L) & $53.1 \pm 24.56^{\mathrm{b}^{*}}$ & $44.35 \pm 21.36$ & $49.85 \pm 19.52$ & $38.65 \pm 22.25$ \\
\hline
\end{tabular}

Data are expressed as mean \pm standard deviation

a: Versus Total PCOS, b: versus IR-PCOS, c: versus NIR-PCOS, ${ }^{*} \mathrm{P}<0.05,{ }^{*} \mathrm{P}<0.01$

Table 1: Anthropometric, biochemical and hormonal characteristics of PCOS women and controls 
Citation: El-Hafez HAA, Elrakhawy MM, El-Aziz SA, El-Eshmawy MM (2013) Thyroid Function and Volume are Associated with Anthropometric Measurements and Insulin Resistance in Egyptian Women with Polycystic Ovary Syndrome. J Diabetes Metab 4: 288. doi:10.4172/21556156.1000288

Page 3 of 5

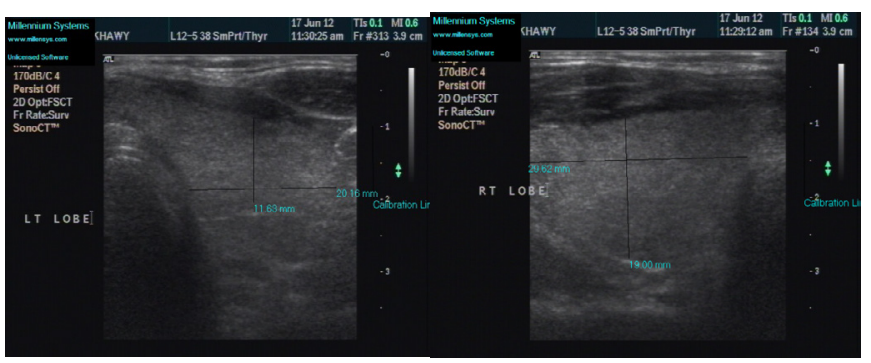

Shows homogeneous echo pattern; left lobe $=6.2$, right lobe $=6.3$, isthmus $=1.8$, Total thyroid volume $=14.3 \mathrm{ml}$

Figure 1: *Transverse section of each thyroid lobe.

\section{Results}

Baseline characteristics are given in Table 1. Total PCOS women had significantly higher WC, systolic blood pressure (SBP), TG, fasting insulin, HOMA-IR $(2.61 \pm 0.86$ vs. $1.65 \pm 0.61, \mathrm{P}<0.01)$, and total testosterone $(2.45 \pm 1.10$ vs. $1.71 \pm 0.72, \mathrm{P}<0.01)$ than control women.

PCOS women were divided, according to HOMA-IR, into 2 subgroups: non-insulin resistant (NIR-PCOS), and insulin resistant PCOS (IR-PCOS). IR-PCOS women showed significantly higher BMI, WC, SBP, TG, fasting insulin, HOMA-IR ( $3.75 \pm 0.81$ vs. 1.65 $\pm 0.61, \mathrm{P}<0.01)$, testosterone $(2.58 \pm 1.30$ vs. $1.71 \pm 0.72, \mathrm{P}<0.01)$, and significantly lower HDL-C, and SHBG (38.65 \pm 22.25 vs. $53.10 \pm 24.56$, $\mathrm{P}<0.05$ ) than in controls (Table 1).

In IR-PCOS women as compared to NIR-PCOS, significantly higher BMI (30.86 \pm 5.93 vs. $27.22 \pm 4.92, \mathrm{P}<0.05)$, WC $(96.50 \pm 13.39$ vs. $88.11 \pm 10.38, \mathrm{P}<0.05)$, TG $(135.11 \pm 32.31$ vs. $114.01 \pm 31.04$, $\mathrm{P}<0.05)$, fasting insulin $(14.91 \pm 3.60$ vs. $7.50 \pm 2.60, \mathrm{P}<0.01)$, and HOMA-IR ( $3.75 \pm 0.81$ vs. $1.75 \pm 0.83, \mathrm{P}<0.01)$ and significantly lower HDL-C (51.20 \pm 7.12 vs. $55.54 \pm 5.21, \mathrm{P}<0.05)$ were found (Table 1$)$.

As compared to controls, IR-PCOS showed significant increase in TSH ( $3.15 \pm 1.34$ vs. $2.29 \pm 0.76, \mathrm{P}<0.05)$, thyroid volume $(16.96 \pm$ 6.80 vs. $12.87 \pm 4.90, \mathrm{P}<0.05)$, and nodule prevalence $(38.8 \%$ vs. $12.9 \%$, $\mathrm{P}<0.05)$. As compared to NIR-PCOS, IR-PCOS displayed significant increase in TSH $(3.15 \pm 1.34$ vs. $2.30 \pm 1.11, \mathrm{P}<0.05)$, and thyroid volume $(16.96 \pm 6.80$ vs.13.01 $\pm 4.51, \mathrm{P}<0.05)$. No significant difference between total PCOS nor NIR-PCOS and controls as regards thyroid function, volume or nodule prevalence. Thyroid nodularity was divided into palpable and non-palpable lesions; no significant difference was found between control, total PCOS, NIR-PCOS and IR-PCOS (Table 2).

In PCOS women, TSH showed significant positive correlations with BMI ( $\mathrm{r}=0.40, \mathrm{P}=0.009)$, WC $(\mathrm{r}=0.35, \mathrm{P}=0.03)$, SBP $(\mathrm{r}=0.389, \mathrm{P}=0.01)$, fasting insulin $(\mathrm{r}=0.38, \mathrm{P}=0.01)$, HOMA-IR $(\mathrm{r}=0.42, \mathrm{P}=0.006)$, TG $(\mathrm{r}=0.37, \mathrm{P}=0.01)$, and testosterone $(\mathrm{r}=0.36, \mathrm{P}=0.03)$. Thyroid volume was positively correlated with $\mathrm{BMI}(\mathrm{r}=0.47, \mathrm{P}=0.002)$, WC $(\mathrm{r}=0.41$, $\mathrm{P}=0.01)$, fasting insulin $(\mathrm{r}=0.46, \mathrm{P}=0.003)$ and HOMA-IR $(\mathrm{r}=0.43$, $\mathrm{P}=0.005)$. Also, thyroid nodule prevalence was positively correlated with BMI $(\mathrm{r}=0.58, \mathrm{P}<0.001)$, WC $(\mathrm{r}=0.42, \mathrm{P}=0.02)$, fasting insulin $(\mathrm{r}=0.47, \mathrm{P}=0.002)$ and HOMA-IR $(\mathrm{r}=0.52, \mathrm{P}=0.001)$ (Table 3$)$.

A multiple regression analysis to assess the independent effect of studied variables on thyroid function and volume in women with PCOS was also performed. BMI, WC, fasting insulin and HOMA remained independently correlated with $\mathrm{TSH}$, thyroid volume and nodule (Table 4).

\section{Discussion}

Limited data are available regarding the relation of insulin resistance with thyroid function and volume in PCOS women. In the current study, thyroid function and volume were assessed in a group of women with PCOS as well as age and BMI matched healthy control women. Only IR-PCOS women had significant increase in TSH and thyroid volume. In PCOS women, thyroid function and volume were associated with insulin resistance, BMI, and waist circumference.

Insulin resistance plays a significant role in PCOS [6]; as many as 50$70 \%$ of PCOS women are insulin resistant [4]. HOMA-IR is a sensitive method for evaluation of IR in PCOS [17], and it was used to identify IR in the present study. Our results showed that IR-PCOS women displayed higher BMI and WC than NIR-PCOS women. These findings supports the relation of obesity and central fat deposition with insulin resistance in PCOS $[6,7,24]$, and suggest that obesity may potentiate IR in PCOS. In addition, we found that triglyceride was higher and HDL-C was lower in IR-PCOS which support the evaluation of insulin resistance in PCOS women to identify increased CV risk [25].

Previous studies tried to explore thyroid changes in PCOS. Mostly the results of these studies showed elevated TSH and higher autoimmune thyroiditis in PCOS women as compared to control women without PCOS [26,27]. A novel finding in the present study is that only IR-PCOS women; but not NIR-PCOS or total PCOS groups; displayed significant increase in TSH level, thyroid volume and nodule prevalence compared to non-PCOS control women. Furthermore, we found that IR-PCOS women had significant increase in TSH and thyroid volume as compared to NIR-PCOS. In contrast, Ozdemir et al. [28] observed that thyroid nodule prevalence and volume did not differ between PCOS patients with and without IR. However, previous studies reported larger thyroid volume and increased nodule prevalence in subjects with IR $[29,11]$ this together with our results support that thyroid changes are linked to IR in PCOS, so that PCOS alone may not associated with thyroid function or volume changes.

In the current study, HOMA-IR in PCOS women had significant positive association and remained independently correlated with TSH. In one study, subclinical hypothyroidism was not associated with IR in PCOS [12], however, another study described that thyroid function as reflected by TSH level $\geq 2 \mathrm{mIU} / \mathrm{L}$ was associated with IR [14]. Thus our results support the relation between IR and thyroid function in PCOS.

IR in PCOS primarily refers to the impaired action of insulin on glucose transport and antilipolysis in adipocytes in the presence of normal insulin binding [30,31], so the relation between IR and thyroid function among PCOS women can be explained by regulatory effects of thyroid hormones on carbohydrate metabolism, gluconeogenesis, lipogenesis and lipolysis. Also they modulate mRNA and protein expression of glucose transporter 4, AMP-activated protein kinase and acetyl CoA carboxylase in skeletal muscle [32]. Taken together with our findings, it can be suggested that thyroid function changes may aggravate IR in PCOS.

Another finding in the current study is that fasting insulin and HOMA-IR were significantly associated and remained independently correlated with thyroid volume and nodularity. In contrast, Cakir et al. [33] found that thyroid volume in PCOS was not associated with hyperinsulinemia or IR. This might be due to inclusion of lean and young PCOS patients in this study. However, In support of our results, Ayturk et al. [29] found that IR was correlated with and a predictor of thyroid volume increase and nodule formation. Insulin receptors are 
Citation: El-Hafez HAA, Elrakhawy MM, El-Aziz SA, El-Eshmawy MM (2013) Thyroid Function and Volume are Associated with Anthropometric Measurements and Insulin Resistance in Egyptian Women with Polycystic Ovary Syndrome. J Diabetes Metab 4: 288. doi:10.4172/21556156.1000288

Page 4 of 5

\begin{tabular}{|c|c|c|c|c|}
\hline Variables & Controls $(n=62)$ & Total PCOS $(n=40)$ & NIR-PCOS $(n=22)$ & IR-PCOS $(n=18)$ \\
\hline $\mathrm{TSH}(\mu \mathrm{lU} / \mathrm{ml})$ & $2.29 \pm 0.76^{\mathrm{b} *}$ & $2.7 \pm 1.23$ & $2.3 \pm 1.11^{\mathrm{b} *}$ & $3.15 \pm 1.34$ \\
\hline FT3 (Pg/ml) & $2.8 \pm 0.80$ & $2.72 \pm 0.69$ & $2.59 \pm 0.67$ & $2.9 \pm 0.54$ \\
\hline FT4 (ng/dl) & $1.4 \pm 0.45$ & $1.35 \pm 0.36$ & $1.46 \pm 0.32$ & $1.23 \pm 0.43$ \\
\hline Thyroid volume (ml) & $12.87 \pm 4.90^{\mathrm{b} *}$ & $14.91 \pm 5.68$ & $13.01 \pm 4.51^{\mathrm{b} *}$ & $16.96 \pm 6.8$ \\
\hline 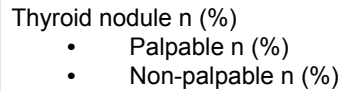 & $\begin{array}{c}8 / 62(12.9 \%)^{b *} \\
3 / 8(37.5 \%) \\
5 / 8(62.5 \%)\end{array}$ & $\begin{array}{l}10 / 40(25 \%) \\
3 / 10(30 \%) \\
7 / 10(70 \%)\end{array}$ & $\begin{array}{l}3 / 22(13.6 \%) \\
1 / 3(33.3 \%) \\
2 / 3(66.6 \%)\end{array}$ & $\begin{array}{l}7 / 18(38.8 \%) \\
2 / 7(28.6 \%) \\
5 / 7(71.4 \%)\end{array}$ \\
\hline
\end{tabular}

Data are expressed as mean \pm standard deviation or percentages

a: versus total PCOS, b: versus IR-PCOS, c: versus NIR-PCOS, ${ }^{*} P<0.05,{ }^{* *} \mathrm{P}<0.01$

Table 2: Thyroid function and volume in PCOS women and controls.

\begin{tabular}{|c|c|c|c|c|c|c|}
\hline \multirow{2}{*}{ Variables } & \multicolumn{2}{|c|}{ TSH } & \multicolumn{2}{|c|}{ Thyroid volume } & \multicolumn{2}{|c|}{ Thyroid nodule } \\
\hline & $r$ & $\mathbf{P}$ & $r$ & $\mathbf{P}$ & $\mathbf{r}$ & $\mathbf{P}$ \\
\hline BMI $\left(\mathrm{kg} / \mathrm{m}^{2}\right)$ & 0.40 & $0.009^{* *}$ & 0.47 & $0.002^{* *}$ & 0.58 & $<0.001^{* *}$ \\
\hline WC $(\mathrm{cm})$ & 0.35 & $0.03^{*}$ & 0.41 & $0.01^{*}$ & 0.42 & $0.02^{*}$ \\
\hline $\mathrm{SBP}(\mathrm{mmHg})$ & 0.38 & $0.01^{*}$ & 0.13 & 0.05 & 0.42 & 0.37 \\
\hline $\mathrm{DBP}(\mathrm{mmHg})$ & 0.11 & 0.49 & 0.11 & 0.48 & 0.04 & 0.69 \\
\hline Fasting insulin $(\mu U / L)$ & 0.38 & $0.01^{*}$ & 0.46 & $0.003^{* *}$ & 0.47 & $0.002^{* *}$ \\
\hline HOMA-IR & 0.42 & $0.006^{\star *}$ & 0.43 & $0.005^{\star *}$ & 0.52 & $0.001^{* *}$ \\
\hline Triglycerides (mg/dl) & 0.37 & $0.01^{*}$ & 0.31 & 0.05 & 0.29 & 0.06 \\
\hline LDL-C (mg/dl) & 0.28 & 0.07 & 0.26 & 0.10 & 0.25 & 0.11 \\
\hline HDL-C (mg/dl) & 0.10 & 0.11 & 0.12 & 0.43 & 0.13 & 0.42 \\
\hline Total Testosterone (nmol/L) & 0.33 & $0.03^{*}$ & 0.26 & 0.09 & 0.11 & 0.47 \\
\hline DHEAS $(\mu \mathrm{mol} / \mathrm{L})$ & 0.28 & 0.07 & 0.15 & 0.36 & 0.15 & 0.40 \\
\hline SHBG (nmol/L) & 0.30 & 0.05 & 0.19 & 0.23 & 0.24 & 0.14 \\
\hline
\end{tabular}

${ }^{*} \mathrm{P}<0.05,{ }^{* *} \mathrm{P}<0.01$

Table 3: Correlation between thyroid function and volume with other parameters in women with polycystic ovary syndrome.

\begin{tabular}{|c|c|c|c|c|c|c|}
\hline \multirow{2}{*}{ Variables } & \multicolumn{2}{|c|}{ TSH } & \multicolumn{2}{|c|}{ Thyroid volume } & \multicolumn{2}{|c|}{ Thyroid nodule } \\
\hline & $\beta$ & $\mathbf{P}$ & $\beta$ & $\mathbf{P}$ & $\beta$ & $\mathbf{P}$ \\
\hline BMI $\left(\mathrm{kg} / \mathrm{m}^{2}\right)$ & 0.31 & $0.04^{*}$ & 0.29 & $0.01^{*}$ & 0.28 & $0.04^{*}$ \\
\hline WC $(\mathrm{cm})$ & 0.35 & $0.02^{*}$ & 0.36 & $0.02^{*}$ & 0.32 & $0.03^{*}$ \\
\hline Fasting insulin $(\mu \mathrm{U} / \mathrm{L})$ & 0.29 & $0.03^{*}$ & 0.58 & $0.009^{* *}$ & 0.52 & $0.02^{*}$ \\
\hline HOMA-IR & 0.37 & $0.01^{*}$ & 0.55 & $0.002^{* *}$ & 0.61 & $0.005^{* *}$ \\
\hline
\end{tabular}

${ }^{*} \mathrm{P}<0.05,{ }^{* *} \mathrm{P}<0.01$

Table 4: Multiple regression analysis with thyroid function and volume as the dependent variables and other parameters as the independent variables in women with polycystic ovary syndrome.

over-expressed in thyroid tissue as an early step in carcinogenesis [34]. There is suggesting evidence that insulin concurrently functions with growth factor and stimulates thyroid cell proliferation [35]. So higher circulating insulin levels may increase thyroid proliferation and induce larger thyroid volume and nodule formation [11].

Adiposity plays a crucial role in maintaining and presumably in generating PCOS. Evidence for this includes the often dramatic improvement in menstrual regularity in response to weight reduction in women with PCOS [36]. Obesity in particular central one is linked to thyroid dysfunction [8]. Increased fat mass may produce more leptin which regulates TRH gene expression that contribute to increased TSH levels [37]. Dittrich et al. [38] revealed that PCOS women with TSH $\geq$ $2.5 \mathrm{mIU} / \mathrm{L}$ had higher BMI in comparison to PCOS women with TSH $<2.5 \mathrm{mIU} / \mathrm{L}$. In accordance, we found that anthropometric measures namely BMI and WC were positively correlated with TSH, thyroid volume and nodularity in PCOS women. Since IR-PCOS women in the present study had higher BMI and WC than NIR-PCOS, we suggest that obesity may potentiate IR in PCOS women through effect on thyroid function, so weight reduction may ameliorate IR in such women.

This study has a benefit of comparing thyroid function and volume in PCOS women with healthy women by presence of IR. Our study did have some limitations. The sample size was small, and adolescents with PCOS were not included. Larger sample with age and BMI stratification can be further studied.

\section{Conclusion}

IR-PCOS women had significant changes in thyroid function and volume compared to NIR-PCOS and control women. Insulin resistance in PCOS women is linked to and associated with TSH and increased thyroid volume and nodularity, so thyroid changes may aggravate IR in PCOS women. Thyroid function and volume in PCOS women are significantly associated with BMI suggesting that obesity may represent a link between IR and thyroid changes in these women.

\section{Author's Contributions}

HAA drafted the manuscript, conceived the study, and participated in its design and coordination. MME carried out thyroid ultrasound, SAA carried out the laboratory studies. MME helped to draft the manuscript and participated in the coordination of the study. All authors read and approved the final manuscript.

\section{Acknowledgment}

The authors thank all sample donors for their contribution to this study and all members of the Endocrinology Unit, Specialized Medical Hospital, Mansoura, Egypt. 
Citation: El-Hafez HAA, Elrakhawy MM, El-Aziz SA, El-Eshmawy MM (2013) Thyroid Function and Volume are Associated with Anthropometric Measurements and Insulin Resistance in Egyptian Women with Polycystic Ovary Syndrome. J Diabetes Metab 4: 288. doi:10.4172/21556156.1000288

Page 5 of 5

\section{References}

1. Asunción M, Calvo RM, San Millán JL, Sancho J, Avila S, et al. (2000) A prospective study of the prevalence of the polycystic ovary syndrome in unselected Caucasian women from Spain. J Clin Endocrinol Metab 85: 2434 2438.

2. Azziz R, Woods KS, Reyna R, Key TJ, Knochenhauer ES, et al. (2004) The prevalence and features of the polycystic ovary syndrome in an unselected population. J Clin Endocrinol Metab 89: 2745-2749.

3. Rotterdam ESHRE/ASRM-Sponsored PCOS Consensus Workshop Group (2004) Revised 2003 consensus on diagnostic criteria and long-term health risks related to polycystic ovary syndrome. Fertil Steril 81: 19-25.

4. Dunaif A (1997) Insulin resistance and the polycystic ovary syndrome: mechanism and implications for pathogenesis. Endocr Rev 18: 774-800.

5. Legro RS (2003) Polycystic ovary syndrome and cardiovascular disease: a premature association? Endocr Rev 24: 302-312.

6. Acién P, Quereda F, Matallín P, Villarroya E, López-Fernández JA, et al. (1999) Insulin, androgens, and obesity in women with and without polycystic ovary syndrome: a heterogeneous group of disorders. Fertil Steril 72: 32-40.

7. Barber TM, McCarthy MI, Wass JA, Franks S (2006) Obesity and polycystic ovary syndrome. Clin Endocrinol (Oxf) 65: 137-145.

8. Reinehr T (2010) Obesity and thyroid function. Mol Cell Endocrinol 316: 165

9. Garduno-Garcia J, Alvirde-Garcia U, Lopez-Carrasco G, Padilla Mendoza ME Mehta R, et al. (2010) TSH and free thyroxine concentrations are associated with differing metabolic markers in euthyroid subjects. Eur J Endocrinol 163 273-278.

10. Kumar HK, Yadav RK, Prajapati J, Reddy CV, Raghunath M, et al. (2009) Association between thyroid hormones, insulin resistance, and metabolic Association between thyroid hormone.

11. Rezzonico J, Rezzonico M, Pusiol E, Pitoia F, Niepomniszcze H (2008) Introducing the thyroid gland as another victim of the insulin resistance syndrome. Thyroid 18: 461-464.

12. Ganie MA, Laway BA, Wani TA, Zargar MA, Nisar S, et al. (2011) Association of subclinical hypothyroidism and phenotype, insulin resistance, and lipid parameters in young women with polycystic ovary syndrome. Fertil Steril 95: 2039-2043.

13. Pallotti S, Gasbarrone A, Franzese IT (2005) [Relationship between insulin secretion, and thyroid and ovary function in patients suffering from polycystic ovary]. Minerva Endocrinol 30: 193-197.

14. Mueller A, Schöfl C, Dittrich R, Cupisti S, Oppelt PG, et al. (2009) Thyroidstimulating hormone is associated with insulin resistance independently of body mass index and age in women with polycystic ovary syndrome. Hum Reprod 24: 2924-2930.

15. Ferriman D, Gallwey JD (1961) Clinical assessment of body hair growth in women. J Clin Endocrinol Metab 21: 1440-1447.

16. Matthews DR, Hosker JP, Rudenski AS, Naylor BA, Treacher DF, et al. (1985) Homeostasis model assessment: insulin resistance and beta-cell function from fasting plasma glucose and insulin concentrations in man. Diabetologia 28 $412-419$

17. Carmina E, Lobo RA (2004) Use of fasting blood to assess the prevalence of insulin resistance in women with polycystic ovary syndrome. Fertil Steril 82 $661-665$.

18. Fulghesu AM, Angioni S, Portoghese E, Milano F, Batetta B, et al. (2006) Failure of the hemostatic model assessment calculation score for detecting metabolic deterioration in young patients with polycystic ovary syndrome. Ferti Steril 86: 398-404.

19. Friedewald WT, Levy RI, Fredrickson DS (1972) Estimation of the concentration of low-density lipoprotein cholesterol in plasma, without use of the preparative ultracentrifuge. Clin Chem 18: 499-502.

20. Runnebaum B, Rabe T (1994) Gynakologische Endokrinologie and Fortpngsmedizin Springer Verag Band 1:17,253-255, Band 2:152-154,360,348. ISBN 3-540-57345-3, ISBN 3-450-57347-X.

21. Winters SJ, Kelley DE, Goodpaster B (1998) The analog free testosterone assay: are the results in men clinically useful? Clin Chem 44: 2178-2182.

22. Teitz NW (1995) Clinical Guide to Laboratory Tests ( $3^{\text {rd }}$ Edn) W.B. Saunders Company, Philadelphia, P. 19106.

23. Sawin CT (1996) Standards of Laboratory Practice: Laboratory support for the diagnosis\& monitoring of thyroid disease. National Academy of Clinical Biochemistry.

24. Puder JJ, Varga S, Kraenzlin M, De Geyter C, Keller U, et al. (2005) Central fat excess in polycystic ovary syndrome: relation to low-grade inflammation and insulin resistance. J Clin Endocrinol Metab 90: 6014-6021.

25. Martins Wde P, Soares GM, Vieira CS, dos Reis RM, de Sá MF, et al. (2009) [Cardiovascular risk markers in polycystic ovary syndrome in women with and without insulin resistance]. Rev Bras Ginecol Obstet 31: 111-116.

26. Sinha U, Sinharay K, Saha S, Longkumer TA, Baul SN, et al. (2013) Thyroid disorders in polycystic ovarian syndrome subjects: A tertiary hospital based cross-sectional study from Eastern India. Indian J Endocrinol Metab 17: $304-$ 309

27. Janssen OE, Mehlmauer N, Hahn S, Offner AH, Gärtner R (2004) High prevalence of autoimmune thyroiditis in patients with polycystic ovary syndrome. Eur J Endocrinol 150: 363-369.

28. Ozdemir D, Cuhaci N, Balkan F, Usluogullari A, Ersoy R, et al. (2011) Prevalence of thyroid pathologies in patients with polycystic ovary syndrome. Endocrine Abstracts 26: 92.

29. Ayturk S, Gursoy A, Kut A, Anil C, Nar A, et al. (2009) Metabolic syndrome and its components are associated with increased thyroid volume and nodule prevalence in a mild-to-moderate iodine-deficient area. Eur J Endocrinol 161 599-605.

30. Marsden PJ, Murdoch A, Taylor R (1994) Severe impairment of insulin action in adipocytes from amenorrheic subjects with polycystic ovary syndrome. Metabolism 43: 1536-1542.

31. Dunaif A, Xia J, Book CB, Schenker E, Tang Z (1995) Excessive insulin receptor serine phosphorylation in cultured fibroblasts and in skeletal muscle. A potential mechanism for insulin resistance in the polycystic ovary syndrome. J Clin Invest 96: 801-810.

32. Crunkhorn S, Patti ME (2008) Links between thyroid hormone action, oxidative metabolism, and diabetes risk? Thyroid 18: 227-237.

33. Cakir E, Sahin M, Topaloglu O, Colak NB, Karbek B, et al. (2012) The relationship between $\mathrm{LH}$ and thyroid volume in patients with PCOS. J Ovarian Res 5: 43.

34. Torrance CJ, Devente JE, Jones JP, Dohm GL (1997) Effects of thyroid hormone on GLUT4 glucose transporter gene expression and NIDDM in rats. Endocrinology 138: 1204-1214.

35. Van Keymeulen A, Dumont JE, Roger PP (2000) TSH induces insulin receptors that mediate insulin costimulation of growth in normal human thyroid cells. Biochem Biophys Res Commun 279: 202-207.

36. Kiddy DS, Hamilton-Fairley D, Bush A, Short F, Anyaoku V, et al. (1992 Improvement in endocrine and ovarian function during dietary treatment of obese women with polycystic ovary syndrome. Clin Endocrinol (Oxf) 36: 105111

37. Feldt-Rasmussen U (2007) Thyroid and leptin. Thyroid 17: 413-419.

38. Dittrich R, Kajaia N, Cupisti S, Hoffmann I, Beckmann MW, et al. (2009) Association of thyroid-stimulating hormone with insulin resistance and androgen parameters in women with PCOS. Reprod Biomed Online 19: 319-325. 